\title{
Prevalence of diagnosed diabetes and associated risk factors: Evidence from the large-scale surveys in India
}

\author{
Saddaf Naaz Akhtar, Preeti Dhillon \\ Department of Mathematical Demography and Statistics, International Institute for Population Sciences, Mumbai, Maharashtra, India
}

\section{A B S T R A C T}

Context: India has observed the most devastating increases in the burden of diabetes in the contemporary era. However, so far, the comparable prevalence of diabetes is only available for limited geography. Aims: The present paper provides comparable estimates of diabetes prevalence in states and districts of India and examines the associated risk factors with newly diagnosed and self-reported diabetes. Setting and Design: The study uses clinical, anthropometric, and biochemical data from District Level Household and Facility Survey (20I2-20I3) and Annual Health Survey (2014). Subjects and Methods: The paper analyses the information on glucose level of the blood sample and defines diabetes as per the World Health Organization (1999) criteria. It applies multinomial logistic regression to identify the risk factors of diabetes. Results: The study estimates $7 \%$ adults with diabetes in India, with a higher level in urban (9.8\%) than in the rural area (5.7\%), a higher proportion of males (7.1\%) than females (6.8\%). Widowed, older persons, and persons with high blood pressure have very high risk of both diagnosed and self-reported diabetes. Comparing to Hindus, Muslims and Christians have higher, and Sikhs have less risk of diabetes. Further, corresponding to general caste, scheduled castes, and other backward classes have a high risk of newly diagnosed but the lower risk of self-reported diabetes. Conclusions: The list of districts and states with alarming diabetes prevalence is the valuable information for further programs and research.A significant population with undiagnosed diabetes reflects an urgent need to strengthen the diagnostics at the local level and for those who need them most.

Key words: Blood glucose level, blood pressure, body mass index, diabetes mellitus, districts, personal habits

\section{INTRODUCTION}

The prevalence of diabetes is swiftly increasing over the globe at an alarming rate. According to the International Federation of Diabetes, 415 million adults around the world are suffering from diabetes, and it is estimated that the numbers will reach around 642 million by $2040 \cdot{ }^{[1]}$ The first World Health Organization (WHO) global report on diabetes demonstrates that the number of adults living with diabetes has almost quadrupled since 1980 to 422

\begin{tabular}{|l|l|}
\hline \multicolumn{2}{|c|}{ Access this article online } \\
\hline Quick Response Code: & Website: \\
\hline & www.josh.net \\
\hline & \\
\hline & \\
\hline
\end{tabular}

million adults. ${ }^{[2]}$ Global age-standardized adult diabetes prevalence was $9.8 \%$ among men and $9.2 \%$ among women in 2008, up from $8.3 \%$ and $7.5 \%$ in $1980 .{ }^{[3]}$ Diabetes has become one of the leading causes of premature illness and deaths in most countries, mainly through the increased risk of cardiovascular disease which is responsible for over $50 \%$ of deaths in persons with diabetes. ${ }^{[4]}$ Although diabetes is sometimes considered the major concern for

This is an open access article distributed under the terms of the Creative Commons Attribution-NonCommercial-ShareAlike 3.0 License, which allows others to remix, tweak, and build upon the work non-commercially, as long as the author is credited and the new creations are licensed under the identical terms.

For reprints contact: reprints@medknow.com

How to cite this article: Akhtar SN, Dhillon P. Prevalence of diagnosed diabetes and associated risk factors: Evidence from the large-scale surveys in India. J Soc Health Diabetes 2017;5:28-36.

Corresponding Author: Dr. Preeti Dhillon, Department of Mathematical Demography and Statistics, International Institute for Population Sciences, Mumbai - 400 088, Maharashtra, India.E-mail: pdhillon.iips@gmail.com 
developed nations, the loss of life from premature death among persons with diabetes is greatest in developing countries. Nearly $80 \%$ of the total adult diabetics are in low- or middle-income countries. ${ }^{[4]}$ India leads the World and stands at the second position after China, with 69 million persons affected by diabetes poses a daunting challenge to the sustainable development of the nation as almost every tenth adult (9.3\%) in India is estimated to be affected by diabetes. ${ }^{[1]}$ The WHO estimated every 26 per 100,000 persons die due to diabetes in India though it declined marginally and for males increased between 2000 and 2012. ${ }^{.5]}$

The primary driver of the epidemic of diabetes is the rapid epidemiological transition associated with changes in dietary patterns and decreased physical activity as evident from the higher prevalence of diabetes in the urban population. ${ }^{[6]}$ This rapid increase is mostly attributed to lifestyle transitions resulting in obesity and physical inactivity, population aging, and urbanization. ${ }^{[7]}$ A study showed that a low-fiber diet with a high glycemic index was positively associated with a higher risk of type 2 diabetes mellitus (DM) ${ }^{[8]}$ Early feeding may also play a subsequent role in the development of type 2 diabetes in later life. ${ }^{[9]}$ Various studies found a strong association between prevalence of diabetes and overweight and obesity. ${ }^{[10]}$ Genetic factors partly determine the risk of type 2 diabetes. ${ }^{[11,12]} \mathrm{A}$ study in India indicates that more than $50 \%$ of people with diabetes have poor glycemic control, uncontrolled hypertension, and dyslipidemia and a large percentage have diabetic vascular complications. ${ }^{[13]}$ Another study on Indian data shows that the common risk factors such as greater duration of diabetes, hypertension, poor metabolic control, smoking, obesity, and dyslipidemia are more prone to develop diabetic complications. ${ }^{[14]}$

Some of the review studies on DM showed a rising trend in the prevalence of diabetes across different parts of India. ${ }^{[6,15]}$ The first national study on the prevalence of type 2 diabetes based on clinical data (blood glucose level $>170 \mathrm{mg} / \mathrm{dl}$ ) in India was done by the Indian Council Medical Research estimated diabetes prevalence of $2.1 \%$ in urban and $1.5 \%$ in the rural area in 1972-1975. ${ }^{[16]}$ A national rural diabetes survey estimated $2.8 \%$ of diabetes (based on the WHO 1985 criteria $\left.^{[17]}\right)$ in 1989-1991. ${ }^{[18]}$ Subsequent studies used the WHO $1999^{[19]}$ criterion estimated a high prevalence of diabetes ranging in rural area from $10 \%$ in $\mathrm{Goa}^{[31]}$ to 19.8 in Karnataka ${ }^{[21]}$ and in an urban area from $9.3 \%$ in Mumbai ${ }^{[7]}$ to $19.5 \%$ in Ernakulam. ${ }^{[22]}$ However, due to lack of clinical data at large scale, available studies provided estimates of DM for the rural, or urban area of selected states or districts and many studies used the different criterion to define DM [Table 1].

The prevalence of DM in India and its states are also available in national health surveys based on self-reported criterion that is respondents reported that they were diagnosed by doctor or others and are available in national health surveys. SAGE $(2013)^{[32]}$ reported 1.9\% among 15-49 and 6.9 among 50 above age persons self-reported diabetes. For the first time, large-scale national level surveys namely district level household and facility survey (DLHS-4, 2012-2013) ${ }^{[33]}$ and Annual Health Survey (AHS, 2014) ${ }^{[34]}$ provide clinical data that includes glucose level results of blood sample tested for adults above age 18 years. Reports from both the surveys provide diabetes prevalence at district and state level. However, both reports adopted different criterion to define diabetes. DLHS-4 reports consider blood glucose level between 140 and $160 \mathrm{mg} / \mathrm{dl}$ for prediabetes and $>160 \mathrm{mg} / \mathrm{dl}$ for moderate to high level of diabetes and AHS provide three estimates for $\geq 110 \mathrm{mg} / \mathrm{dl}, \geq 130$ and $\geq 150$ level of blood glucose. Both surveys collected fasting blood sample from individuals; however, DLHS-4 data also include result from a random blood sample although it collected only one blood sample from each individual (either fasting or random). It is manifested from the above literature review that there is an urgent need to access the increasing burden of diabetes and its associated risk factors using the recent available large-scale clinical surveys in India. Therefore, the present paper aims to provide the comparable prevalence rates DM for all covered states and districts in India using the WHO 1999 criterion. In the developing countries including India, a higher proportion of diabetes is undiagnosed. Therefore, the present study examines the risk factors of newly diagnosed and self-reported (previously diagnosed) DM in select states of India.

\section{SUBJECTS AND METHODS}

We use clinical, anthropometric, and biochemical (CAB) data from DLHS (DLHS-4, 2012-2013) and AHS (AHS, 2014). DLHS-4 is the fourth round in the series following Reproductive and Child Health (RCH-I) in 1988-1999, RCH-II in 2002-2004, and DLHS-3 in 2007-2008. DLHS-4 adopts a multistage stratified sampling design and cover district representative sample and provides data for 18 states and 3 union territories (UTs) consisting 271 districts. Whereas, AHS data cover all 284 districts of the eight empowered action group states, namely Bihar, Chhattisgarh, Jharkhand, Madhya Pradesh, Odisha, Rajasthan, Uttarakhand, Uttar Pradesh, and Assam. 


\begin{tabular}{|c|c|c|c|c|c|c|}
\hline Study & Survey year & Study area & Type of residence & Sample (age) & Prevalence & Definition criterion \\
\hline 23 & 1994-1995 & Guwahati & Urban & $1016(\geq 20)$ & 8.3 & WHO 1985 \\
\hline 24 & 1998 & Thiruvananthapuram & & $2000(\geq 20)$ & 16.3 & WHO 1985 \\
\hline 25 & 1999-2002 & National & Total & $18,363(\geq 25)$ & 4.3 & WHO 1999 \\
\hline 20 & 1999 & Kashmir Valley & Total & $40+$ & 6.1 & WHO 1999 \\
\hline 7 & 2000 & New Delhi & Urban & $11,216(\geq 20)$ & 10.3 & WHO 1999 \\
\hline 7 & 2000 & Kolkata & Urban & $11,216(\geq 20)$ & 11.7 & WHO 1999 \\
\hline 7 & 2000 & Hyderabad & Urban & $11,216(\geq 20)$ & 16.6 & WHO 1999 \\
\hline 7 & 2000 & Mumbai & Urban & $11,216(\geq 20)$ & 9.3 & WHO 1999 \\
\hline 7 & 2000 & Chennai & Urban & $11,216(\geq 20)$ & 13.5 & WHO 1999 \\
\hline 7 & 2000 & Bengaluru & Urban & $11,216(\geq 20)$ & 12.4 & WHO 1999 \\
\hline 26 & $2002-2003$ & Industries from different sites in India & Urban & $10,930(20-69)$ & 10.1 & WHO 1999 \\
\hline 27 & $2001-2002$ & Jaipur & Urban & $1800(\geq 20)$ & 8.6 & WHO 1999 \\
\hline 28 & 2005 & Rural India & Rural & $4535(\geq 30)$ & 13.2 & ADA \\
\hline 22 & 2004-2005 & Ernakulam & Total & $3069(18-80)$ & 19.5 & WHO \\
\hline 29 & 2007 & Central Kerala & Rural & $1645(\geq 20)$ & 12.5 & WHO 1999 \\
\hline 30 & $2008-2009$ & Chandigarh & Urban & $2227(\geq 20)$ & 11.1 & WHO 1999 \\
\hline 21 & 2009-2010 & Karnataka & Rural & $1370(\geq 20)$ & 19.8 & WHO 1999 \\
\hline 31 & Not available & Goa & Rural & $1266(\geq 20)$ & 10.3 & ADA \\
\hline
\end{tabular}

WHO $=$ World Health Organization, ADA $=$ American Diabetes Association

These states are economically and demographically backward. CAB data for two states Jammu and Kashmir, and Gujarat and four UTs are not available in any of these surveys. Therefore, the present paper analyses data for 27 out of 29 states and 3 out of 7 UTs in India which constitute more than $92 \%$ of the adult population of India. More information about both surveys is available elsewhere. ${ }^{[33,34]}$

Both surveys took informed consent from all individuals before the blood sample was taken for $\mathrm{CAB}$ and blood glucose level was tested for all eligible persons above the age of 18 years. Table 2 presents the sample distribution for both $\mathrm{CAB}$ surveys. After exclusion of refused, not present at home, other values and out of range sample, DLHS-4 constitutes 824,703 individuals and AHS 875,711 individuals. Refusal rate (including a small proportion of not present at home and other values) is nearly 20\% in DLHS and $12 \%$ in AHS. We observe the significant differentials in response rate by background characteristics as comparatively more females, and older persons agreed to give their blood sample in both the surveys. The refusal rate is higher in rural areas of DLHS sample though these differences were less prominent in AHS sample. To overcome differentials in refusal rate, we adjust sampling weights with this response rates by sex, age group, and place of residence at the district level. Appropriate sampling weights are applied for estimating prevalence rates. To make prevalence comparable, we also provide age-standardized prevalence rates where we consider the age-specific population for India from census 2011 as a standard population. Whole analysis was done using STATA (version 13) and geographic maps were prepared in Arc GIS-10.
We estimate diagnosed diabetes prevalence rates for all covered states, UTs, and districts and self-reported diabetes prevalence for all covered states and UTs. We adopted the WHO (1999) 20 definition that considers blood glucose level $\geq 126 \mathrm{mg} / \mathrm{dl}$ for fasting blood sample or $\geq 200 \mathrm{mg} / \mathrm{dl}$ for a random blood sample to define a person as diabetic. Both surveys took only one blood sample for each while AHS collected fasting and DLHS took either fasting or random blood sample from all eligible individuals. Self-reporting in both the surveys is defined as whether a person reported being diagnosed diabetes in last 1 year.

The study applies multinomial logistic regression to predict the association of risk factors with the three possible diabetic categories, namely newly diagnosed diabetes (NDD) only, self-reported diabetic only, and both diagnosed and self-reported DM. Those who were neither newly diagnosed nor self-reported are taken as a reference category. Multinomial logistic regression is a simple extension of binary logistic regression that allows for more than two categories of the dependent or outcome variable. Multinomial logistic regression uses likelihood estimation to evaluate the probability of categorical membership.

\section{Independent variables}

Based on the review of determinants of DM highlighted in the introduction section and considering the relevance in the context of India, the potential factors included are age, sex, marital status, years of schooling, religion, caste and urbanized states/UTs, and body mass index (BMI). Among the various personal habits, the study includes smoking habits and use of alcohol. Further, the study also considers disability status to examine the association in particular with newly diagnosed diabetic cases. 


\begin{tabular}{|c|c|c|c|c|}
\hline & Measured & Refusal* & $\begin{array}{l}\text { Out of } \\
\text { range }^{\star \star}\end{array}$ & $\begin{array}{l}\text { Total sample } \\
\text { for CAB }\end{array}$ \\
\hline \multicolumn{5}{|l|}{ Background } \\
\hline \multicolumn{5}{|l|}{ Sex } \\
\hline Male & 45.3 & 60.2 & 47.1 & 48.2 \\
\hline Female & 54.7 & 39.8 & 52.9 & 51.8 \\
\hline \multicolumn{5}{|l|}{$\begin{array}{l}\text { Place of } \\
\text { residence }\end{array}$} \\
\hline Rural & 60.2 & 57.5 & 56.5 & 59.7 \\
\hline Urban & 39.8 & 42.5 & 43.5 & 40.4 \\
\hline \multicolumn{5}{|l|}{ Age group } \\
\hline $18-29$ & 28.8 & 37.0 & 30.9 & 30.5 \\
\hline $30-39$ & 22.0 & 20.4 & 19.7 & 21.7 \\
\hline $40-49$ & 18.6 & 16.0 & 17.7 & 18.1 \\
\hline $50-59$ & 14.4 & 12.7 & 14.6 & 14.1 \\
\hline 60 plus & 16.1 & 14.0 & 17.1 & 15.7 \\
\hline \multicolumn{5}{|l|}{ Education } \\
\hline Nonliterate & 33.0 & 26.8 & 35.2 & 31.8 \\
\hline$<5$ & 12.1 & 9.9 & 10.9 & 11.7 \\
\hline $6-8$ & 15.4 & 14.5 & 14.3 & 15.2 \\
\hline $9-10$ & 16.4 & 17.5 & 15.8 & 16.6 \\
\hline 11 or more & 23.1 & 31.3 & 23.8 & 24.8 \\
\hline Total (\%) & 79.29 & 19.85 & 0.86 & 100 \\
\hline Sample (DLHS-4) & 824,703 & 206,403 & 8952 & $1,031,355$ \\
\hline \multicolumn{5}{|l|}{ SEX } \\
\hline Male & 46.5 & 60.5 & 59.6 & 48.8 \\
\hline Female & 53.5 & 39.5 & 40.4 & 51.2 \\
\hline \multirow{2}{*}{\multicolumn{5}{|c|}{$\begin{array}{l}\text { Place of } \\
\text { Residence }\end{array}$}} \\
\hline & & & & \\
\hline Rural & 81.5 & 78.7 & 83.2 & 81.2 \\
\hline Urban & 18.5 & 21.3 & 16.8 & 18.8 \\
\hline \multicolumn{5}{|l|}{ Age group } \\
\hline $18-29$ & 31.2 & 44.3 & 43.0 & 33.3 \\
\hline $30-39$ & 22.4 & 19.5 & 19.7 & 21.9 \\
\hline $40-49$ & 18.3 & 14.5 & 14.1 & 17.6 \\
\hline $50-59$ & 13.1 & 9.6 & 10.4 & 12.5 \\
\hline 60 plus & 15.2 & 12.1 & 12.9 & 14.7 \\
\hline Total (\%) & 83.46 & 11.88 & 4.66 & 100 \\
\hline Sample (AHS) & 875,711 & 124,672 & 48,912 & $1,049,295$ \\
\hline
\end{tabular}

BMI classification: Cases were classified using classification recommended for Asians for BMI. Categories according to the classification were $<18.50 \mathrm{~kg} / \mathrm{m}^{2}$ as underweight, $18.5-24.99 \mathrm{~kg} / \mathrm{m}^{2}$ as normal, $25.00-29.99 \mathrm{~kg} / \mathrm{m}^{2}$ as overweight, and $30.00 \mathrm{~kg} / \mathrm{m}^{2}$ above as obese (WHO expert consultation 2004). ${ }^{[36]}$

The study also uses a proxy measure of income, i.e., wealth index as an independent variable. Dummies (26 in rural and 22 in urban) for different household assets and conditions were used in the principal component analysis to construct wealth index. First principal component explained a large proportion, i.e., $19 \%$ approximately variations in the data. Moreover, we classify states/UTs on the basis of percent urban into two categories.

\section{RESULTS}

Table 3 presents the prevalence of diagnosed and self-reported DM for all covered states and UTs. We estimate $7.0 \%$ adults with diagnosed diabetes in India, a higher prevalence for males (7.1\%) than females $(6.8 \%)$ and urban $(9.8 \%)$ than rural $(5.7 \%)$ residents. Of the 21, 9 states and UTs show over 10\% (age-standardized) prevalence of diagnosed DM. It is highest in Goa (17.7\%) followed by Puducherry (16.9\%), Tamil Nadu (16.1\%), Kerala (13.6\%), and Chandigarh (11.5\%). It is noteworthy that these states are urbanized states and in the advanced stage of demographic and epidemiological transition. On the other hand, states such as Bihar, Madhya Pradesh, Odisha, and Himachal Pradesh show $<3.5 \%$ of diagnosed diabetes among adults.

Further, India shows only $1.3 \%$ of adults with self-reported diabetes. The age-standardized prevalence of self-reported diabetes is highest in adults from Goa (5\%), followed by Kerala (4.2\%) and Chandigarh (3\%). Andhra Pradesh, Puducherry, and Punjab also show more than $2 \%$ of self-reported diabetes among adults. Goa and Kerala are the states with a higher prevalence of self-reported, as well as diagnosed diabetes. It is noteworthy to mention that Tamil Nadu, Puducherry, Goa, and Tripura have significant gaps between self-reported and diagnosed prevalence of diabetes.

The study also provides district level age-standardized estimates for diagnosed diabetes shown in Figure 1. There are 28 districts; all from the Southern part of India highlighted in dark red have $16 \%$ or above adults with diagnosed diabetes. Further, most of the districts in the second highest range (12.0-15.9) of diabetes prevalence are from Southern India and six from West Bengal, and three are from Maharashtra. Further, districts 84 out of 577 from all over India show the prevalence of diagnosed diabetes between $8.0 \%$ and $11.9 \%$. It is also noteworthy to mention that 227 out of 577 districts in India have $<4 \%$ adults with diabetes. Most of these districts belong to North or Central part of India.

Risk factors of newly diagnosed and self-reported diabetes mellitus

Table 4 presents the results of multinomial logistic regression applied to determine the risk factors associated with diabetes among adults. Comparing to males, females' relative risk ratio (RRR) of "newly diagnosed" $(0.95$, $P<0.01)$, "self-reported only" $(0.88, P<0.01)$, and both 


\begin{tabular}{|c|c|c|c|c|c|c|c|c|c|c|}
\hline & \multicolumn{5}{|c|}{ Diagnosed diabetes } & \multicolumn{5}{|c|}{ Self-reported diabetes } \\
\hline & \multicolumn{2}{|c|}{ Crude prevalence } & \multicolumn{2}{|c|}{ Age-standardized } & \multirow[t]{2}{*}{ Sample } & \multicolumn{2}{|c|}{ Crude prevalence } & \multicolumn{2}{|c|}{ Age-standardized } & \multirow[t]{2}{*}{ Sample } \\
\hline & Percentage & Cl $95 \%$ & Percentage & Cl 95\% & & Percentage & Cl 95\% & Percentage & $\mathrm{Cl} 95 \%$ & \\
\hline Puducherry & 18.7 & $16.9,20.7$ & 16.9 & $15.1,18.9$ & 12,156 & 2.5 & $1.4,4.6$ & 2.2 & $1.1,4.1$ & 15,568 \\
\hline Tamil Nadu & 17.7 & $16.7,18.8$ & 16.1 & $15.2,17.1$ & 103,822 & 1.8 & $1.6,2$ & 1.5 & $1.3,1.7$ & 128,251 \\
\hline Kerala & 14.9 & $12.9,17.3$ & 13.6 & $11.5,15.9$ & 36,791 & 5.1 & $4.1,6.4$ & 4.2 & $3.4,5$ & 56,835 \\
\hline Chandigarh & 11.7 & $11.3,12.1$ & 11.5 & $10.3,12.7$ & 3371 & 2.9 & $2.4,3.7$ & 3.1 & $2.8,3.4$ & 3883 \\
\hline Tripura & 11.2 & $9.9,12.8$ & 11.3 & $10,12.8$ & 10,124 & 0.7 & $0.5,1$ & 0.7 & $0.5,1$ & 11,900 \\
\hline Karnataka & 11.5 & $10.4,12.7$ & 11.1 & $10,12.2$ & 107,289 & 1.7 & $1.4,2.2$ & 1.6 & $1.3,2.1$ & 153,218 \\
\hline West Bengal & 11.1 & $9.9,12.4$ & 10.6 & $9.5,11.9$ & 48,784 & 1.2 & 1, 1.5 & 1.2 & $1,1.5$ & 79,824 \\
\hline Andhra Pradesh & 10.9 & $9.5,12.5$ & 10.2 & $8.8,11.7$ & 41,781 & 2.8 & $2.4,3.3$ & 2.5 & $2.1,2.9$ & 59,152 \\
\hline $\begin{array}{l}\text { Andaman and Nicobar } \\
\text { Islands }\end{array}$ & 9.5 & $8.6,10.5$ & 9.1 & $8,10.3$ & 5194 & 2 & $1.1,3.8$ & 2 & $0.9,4.1$ & 7023 \\
\hline Telangana & 9.0 & $7.7,10.5$ & 8.8 & $7.5,10.4$ & 29,620 & 1.4 & 1, 1.8 & 1.3 & $1,1.7$ & 41,083 \\
\hline Manipur & 9.1 & $8.2,10$ & 8.5 & $7.7,9.3$ & 21,182 & 1.1 & $0.7,1.7$ & 1 & $0.6,1.5$ & 26,884 \\
\hline Punjab & 8.7 & $8.1,9.3$ & 8.3 & $7.7,8.9$ & 91,455 & 2.4 & $2.1,2.6$ & 2.2 & $2,2.4$ & 113,144 \\
\hline Haryana & 6.6 & $5.9,7.5$ & 6.5 & $5.7,7.4$ & 77,524 & 1.8 & $1.5,2.2$ & 1.8 & $1.4,2.1$ & 110,742 \\
\hline Nagaland & 6.9 & $6.1,7.9$ & 6.3 & $5.5,7.3$ & 20,146 & 0.1 & $0.1,0.3$ & 0.1 & $0.1,0.2$ & 27,759 \\
\hline Maharashtra & 6.5 & $5.7,7.4$ & 6.1 & $5.4,7$ & 114,041 & 1.4 & $1.2,1.7$ & 1.3 & $1.1,1.5$ & 172,820 \\
\hline Sikkim & 6.0 & $4.8,7.5$ & 6.0 & $4.8,7.4$ & 9284 & 1.5 & $1.2,2$ & 1.6 & $1.1,2.1$ & 11,857 \\
\hline Chhattisgarh & 5.4 & $4.2,6.8$ & 5.4 & $4.2,6.8$ & 55,594 & 0.9 & $0.7,1.3$ & 0.9 & $0.7,1.3$ & 667,262 \\
\hline Uttarakhand & 4.9 & $3.4,7$ & 4.8 & $3.3,7$ & 35,546 & 1.4 & $1.0,1.9$ & 1.3 & $0.9,1.8$ & 842,190 \\
\hline Mizoram & 4.4 & $3.6,5.3$ & 4.4 & $3.6,5.4$ & 22,195 & 0.4 & $0.2,0.5$ & 0.4 & $0.3,0.5$ & 23,494 \\
\hline Assam & 4.4 & $3.6,5.3$ & 4.3 & $3.7,5$ & 72,156 & 1.5 & $1.3,1.8$ & 1.5 & $1.3,1.8$ & 884,238 \\
\hline Rajasthan & 4.2 & $3.6,4.9$ & 4.1 & $3.5,4.8$ & 81,261 & 0.7 & $0.4,0.6$ & 0.7 & $0.6,0.9$ & 844,170 \\
\hline Arunachal Pradesh & 3.9 & $2.9,5.2$ & 4.0 & $3,5.4$ & 33,856 & 0.4 & $0.3,0.6$ & 0.5 & $0.3,0.6$ & 44,826 \\
\hline Uttar Pradesh & 3.8 & $3.5,4.2$ & 3.8 & $3.5,4.2$ & 206,247 & 0.8 & $0.7,0.9$ & 0.8 & $0.7,0.9$ & $2,063,050$ \\
\hline Meghalaya & 3.5 & $2.3,5.3$ & 3.7 & $2.4,5.6$ & 12,166 & 0.3 & $0.2,0.5$ & 0.3 & $0.2,0.5$ & 19,884 \\
\hline Jharkhand & 3.7 & $2.9,4.8$ & 3.6 & $2.8,4.7$ & 50,711 & 1.3 & $0.9,1.9$ & 1.3 & $0.9,1.9$ & 713,303 \\
\hline Himachal Pradesh & 3.8 & $3.1,4.6$ & 3.4 & $2.8,4.1$ & 19,106 & 0.5 & $0.4,0.7$ & 0.5 & $0.3,0.6$ & 36,028 \\
\hline Odisha & 3.8 & $3.4,4.4$ & 3.4 & $3.1,3.9$ & 104,273 & 1.6 & $1.3,1.9$ & 1.4 & $1.2,1.7$ & $1,048,708$ \\
\hline Madhya Pradesh & 3.1 & $2.6,3.7$ & 3.1 & $2.6,3.6$ & 140,518 & 0.7 & $0.5,0.9$ & 0.7 & $0.6,0.9$ & $1,159,006$ \\
\hline Bihar & 2.6 & $2.2,3.1$ & 2.6 & $2.1,3.1$ & 129,405 & 0.7 & $0.6,0.9$ & 0.7 & $0.6,0.9$ & $1,220,692$ \\
\hline India & & & 7.0 & & & & & 1.3 & & \\
\hline
\end{tabular}

Standard population: Age-specific adults' population of India (excluding Jammu and Kashmir and Gujarat) from Census of India. $\mathrm{Cl}=\mathrm{Confidence} \mathrm{interval}$

"diagnosed and self-reported" $(0.97, P<0.01)$ diabetes is lesser. Diabetes is positively associated with age. Comparing to the youngest age group, 60 and above older people are at higher risk of newly diagnosed $(3.2, P<0.01)$ and "self-reported only" $(29.9, P<0.01)$ and strikingly their risk for both diagnosed and self-reported diabetes is quite high (RRR, 47.1; $P<0.01$ ). Widows or widowers have a significantly higher RRR, 1.3 for newly diagnosed, 2.1 for "self-reported only," and 2.2 for both "diagnosed and self-reported" diabetes in contrast to unmarried adults. Comparing to rural, urban residents have a higher RRR 1.2 for "newly diagnosed," 1.7 for "self-reported only," and 1.8 for both "diagnosed and self-reported" diabetes. Similarly, adults from urbanized states and UTs have 1.2 RRRs of newly diagnosed and 1.1 times the risk of self-reported diabetes in comparison to adults from less urbanized states and UTs.

Households' affluent level shows a positive association with diabetes prevalence though interestingly, family income is not strongly associated with the risk of NDDs. Comparing to the poorest households, persons from the richer and the most affluent households have a higher RRR, 1.9 and 2.7 of "self-reported only" and (RRR, 2.5 and 3.0) of "diagnosed and self-reported" diabetes. Similarly, education has a positive effect on diabetes prevalence though the RRR among educated persons is more prominent for "self-reported only" and "diagnosed and self-reported" diabetes.

Comparing to Hindus, Muslims have higher RRR, 1.1 for "newly diagnosed" and 1.3 for "self-reported only" diabetes. Further, in contrast to Hindus, Christians also have more risk (1.3 times) of "self-report only" diabetes and strikingly, Sikhs have a lower risk 0.82 of "newly diagnosed" and 0.9 for "self-reported only" diabetes. One of the crucial findings of the study is that comparing to general caste, persons from scheduled caste (SCs) and other backward classes (OBCs) have more than 1.1 times risks of newly diagnosed and less risk (0.8 for SCs, 0.9 for OBCs) of "self-reported only" diabetes.

Further, results show that obese respondents have two times risk for "newly diagnosed" and 1.5 for "self-reported 


\begin{tabular}{|c|c|c|c|c|c|c|}
\hline \multirow{2}{*}{$\begin{array}{l}\text { Backgrounds } \\
\text { characteristics }\end{array}$} & \multicolumn{2}{|c|}{ Newly diagnosed diabetes } & \multicolumn{2}{|c|}{ Reported diabetes only } & \multicolumn{2}{|c|}{ Diagnosed and reported (both) } \\
\hline & RRR & Cl $95 \%$ & RRR & $\mathrm{Cl} 95 \%$ & RRR & CI $95 \%$ \\
\hline \multicolumn{7}{|l|}{ Sex } \\
\hline \multicolumn{7}{|l|}{ Male } \\
\hline Female & $0.95^{\star * *}$ & $0.94,0.97$ & $0.88^{* * *}$ & $0.83,0.92$ & $0.97^{* * *}$ & $0.92,1.03$ \\
\hline \multicolumn{7}{|l|}{ Age group } \\
\hline \multicolumn{7}{|l|}{$18-29$} \\
\hline $30-39$ & $1.6 * * *$ & $1.55,1.65$ & $4.49 * * *$ & $3.67,5.5$ & $5.93 * * *$ & $4.49,7.84$ \\
\hline $40-49$ & $2.41 * * *$ & $2.34,2.49$ & $14.46^{* * *}$ & 11.91, 17.56 & $22.06 * * *$ & $16.86,28.86$ \\
\hline $50-59$ & $3.24^{* * *}$ & $3.13,3.35$ & $29.86 * * *$ & $24.61,36.24$ & $47.09 * * *$ & $36.02,61.54$ \\
\hline \multicolumn{7}{|l|}{ Marital status } \\
\hline \multicolumn{7}{|l|}{ Unmarried } \\
\hline Married & $1.21 * * \star$ & $1.17,1.25$ & $1.7^{\star * *}$ & $1.4,2.06$ & $1.95^{\star \star *}$ & $1.53,2.48$ \\
\hline Widow & $1.26 * * \star$ & $1.2,1.31$ & $2.05^{\star \star *}$ & $1.68,2.5$ & $2.17^{* * *}$ & $1.69,2.78$ \\
\hline Divorce/separated & $1.08^{*}$ & $0.99,1.19$ & $2.2^{* \star \star}$ & $1.63,2.96$ & $2 * \star \star$ & $1.38,2.89$ \\
\hline \multicolumn{7}{|l|}{ Wealth index } \\
\hline \multicolumn{7}{|l|}{ Poorest } \\
\hline Poorer & $1.05^{\star * *}$ & $1.02,1.08$ & $1.32^{* * *}$ & $1.19,1.45$ & $1.53^{* * *}$ & $1.36,1.72$ \\
\hline Middle & $1.09 * * *$ & $1.06,1.12$ & $1.62 * \star \star$ & $1.48,1.78$ & $2.00 * * \star$ & $1.79,2.23$ \\
\hline Richer & $1.07 * * *$ & $1.04,1.1$ & $1.94 * * *$ & $1.78,2.13$ & $2.45^{\star \star *}$ & $2.2,2.72$ \\
\hline Richest & $1.00^{\star}$ & $0.97,1.03$ & $2.66 * * *$ & $2.43,2.91$ & $2.97 * * *$ & $2.67,3.31$ \\
\hline \multicolumn{7}{|l|}{ Place } \\
\hline \multicolumn{7}{|l|}{ Rural $^{\ddagger}$} \\
\hline Urban & $1.19 * \star *$ & $1.17,1.21$ & $1.66^{* * *}$ & $1.58,1.74$ & $1.75^{\star \star \star}$ & $1.67,1.85$ \\
\hline Urban states & & & & & & \\
\hline Low $^{\ddagger}$ & & & & & & \\
\hline High & $1.24 * * *$ & $1.22,1.26$ & $1.12 * \star \star$ & $1.06,1.17$ & $1.05^{\star *}$ & $1,1.11$ \\
\hline $\begin{array}{l}\text { Education } \\
\text { Illiterate }\end{array}$ & & & & & & \\
\hline Primary & $1.05^{\star \star *}$ & $1.01,1.08$ & 1.06 & $0.97,1.16$ & $1.13^{* *}$ & $1.03,1.25$ \\
\hline Middle & $1.07^{* * *}$ & $1.04,1.11$ & $1.1^{\star \star}$ & $1,1.2$ & $1.12 * *$ & $1.01,1.23$ \\
\hline Secondary/HS & $1.06^{* * *}$ & $1.03,1.09$ & $1.1^{* * *}$ & $1.01,1.21$ & $1.13^{* * *}$ & $1.03,1.24$ \\
\hline Graduate/above & $1.05^{\star \star \star}$ & $1.02,1.09$ & $1.19 * \star \star$ & $1.07,1.31$ & 1.01 & $0.9,1.13$ \\
\hline Religion & & & & & & \\
\hline Hindu* & & & & & & \\
\hline Muslim & $1.09 * * *$ & $1.06,1.12$ & $1.25^{\star \star *}$ & $1.16,1.35$ & $1.3^{* * *}$ & $1.2,1.41$ \\
\hline Christian & 0.99 & $0.96,1.02$ & $1.11^{\star *}$ & $1.01,1.22$ & $1.27 * \star \star$ & $1.15,1.41$ \\
\hline Sikh & $0.82^{* \star *}$ & $0.79,0.84$ & $0.9^{* *}$ & $0.83,0.98$ & $0.93^{*}$ & $0.85,1.01$ \\
\hline Other & $0.6^{\star * *}$ & $0.57,0.64$ & $0.82^{* *}$ & $0.7,0.95$ & $0.71^{* * *}$ & $0.59,0.86$ \\
\hline Caste & & & & & & \\
\hline General $^{\ddagger}$ & & & & & & \\
\hline SC & $1.13^{\star * *}$ & $1.1,1.15$ & $0.82^{* * *}$ & $0.77,0.88$ & $0.86^{* * *}$ & $0.8,0.92$ \\
\hline ST & $0.77^{* * *}$ & $0.74,0.79$ & $0.38^{* * *}$ & $0.34,0.42$ & $0.29 * * *$ & $0.26,0.33$ \\
\hline $\mathrm{OBC}$ & $1.16^{\star \star \star}$ & $1.14,1.19$ & $0.91^{* \star *}$ & $0.86,0.96$ & 1.03 & $0.98,1.09$ \\
\hline BMI & & & & & & \\
\hline Normal ${ }^{\ddagger}$ & & & & & & \\
\hline Underweight & $0.88 * * *$ & $0.86,0.91$ & $0.63^{* * *}$ & $0.58,0.68$ & $0.52^{* * *}$ & $0.47,0.58$ \\
\hline Overweight & $1.57^{* * *}$ & $1.54,1.6$ & $1.31^{* * *}$ & $1.24,1.38$ & $1.83^{* * *}$ & $1.74,1.94$ \\
\hline Obese & $2.03^{* * *}$ & $1.97,2.08$ & $1.51^{* * *}$ & $1.41,1.63$ & $2.15^{\star \star *}$ & $2,2.31$ \\
\hline $\begin{array}{l}\text { Hypertension } \\
\text { Ideal }^{\ddagger}\end{array}$ & & & & & & \\
\hline Low & $1.25^{\star \star *}$ & $1.2,1.31$ & 1.04 & $0.89,1.23$ & 1.15 & $0.94,1.4$ \\
\hline Prehigh & $1.17^{\star \star \star}$ & $1.14,1.19$ & $1.27 * \star *$ & $1.19,1.36$ & $1.3^{\star * *}$ & $1.2,1.41$ \\
\hline High & $1.6^{* \star *}$ & $1.56,1.63$ & $1.42^{\star * *}$ & $1.32,1.51$ & $2.03^{* * *}$ & $1.88,2.19$ \\
\hline Any disability & & & & & & \\
\hline No disability & & & & & & \\
\hline Disability & $1.17^{\star \star *}$ & $1.13,1.21$ & $1.5^{\star \star \star}$ & $1.38,1.63$ & $1.15^{\star \star *}$ & $1.04,1.27$ \\
\hline Smoking habit & & & & & & \\
\hline Never & & & & & & \\
\hline Usual smoker & $0.96^{* *}$ & $0.93,1$ & 0.92 & $0.83,1.02$ & $0.72^{\star *}$ & $0.63,0.82$ \\
\hline Occasionally & $0.96^{* *}$ & $0.92,1$ & 1.1 & $0.98,1.23$ & $0.79^{\star *}$ & $0.69,0.91$ \\
\hline Ex-smoker & $1.07^{\star *}$ & $1.01,1.12$ & $1.2^{* * *}$ & $1.05,1.37$ & 1.08 & $0.94,1.26$ \\
\hline Alcohol consumption & & & & & & \\
\hline Never & & & & & & \\
\hline Usually & 0.99 & $0.95,1.03$ & 1 & $0.89,1.12$ & 1.06 & $0.94,1.21$ \\
\hline & & & & & & Con \\
\hline
\end{tabular}




\begin{tabular}{|c|c|c|c|c|c|c|}
\hline \multirow{2}{*}{$\begin{array}{l}\text { Backgrounds } \\
\text { characteristics }\end{array}$} & \multicolumn{2}{|c|}{ Newly diagnosed diabetes } & \multicolumn{2}{|c|}{ Reported diabetes only } & \multicolumn{2}{|c|}{ Diagnosed and reported (both) } \\
\hline & RRR & $\mathrm{Cl} 95 \%$ & RRR & $\mathrm{Cl} 95 \%$ & RRR & $\mathrm{Cl} 95 \%$ \\
\hline Occasionally & $0.88 * * *$ & $0.85,0.91$ & 0.98 & $0.89,1.07$ & $1^{*}$ & $0.9,1.11$ \\
\hline Ex-alcoholic & 1.01 & $0.96,1.07$ & 1.05 & $0.92,1.19$ & 1.14 & $0.99,1.31$ \\
\hline$n$ & & & & $216^{\#}$ & & \\
\hline
\end{tabular}

${ }^{* * \star} P<0.01,{ }^{*} P<0.5,{ }^{*} P<0.1$; individuals with no diabetes category is reference of dependent variable. ${ }^{*}$ Is taken as reference variable; ${ }^{*}$ Excluded not known and missing cases in four independent variables (marital status, education, smoking, and alcohol). BMI = Body mass index, $\mathrm{Cl}=\mathrm{Confidence} \mathrm{interval,} \mathrm{RRR}=\mathrm{Relative} \mathrm{risk} \mathrm{ratio,}$ $\mathrm{HS}=$ Higher secondary, $\mathrm{OBC}=$ Other backward class, $\mathrm{SC}=$ Scheduled caste

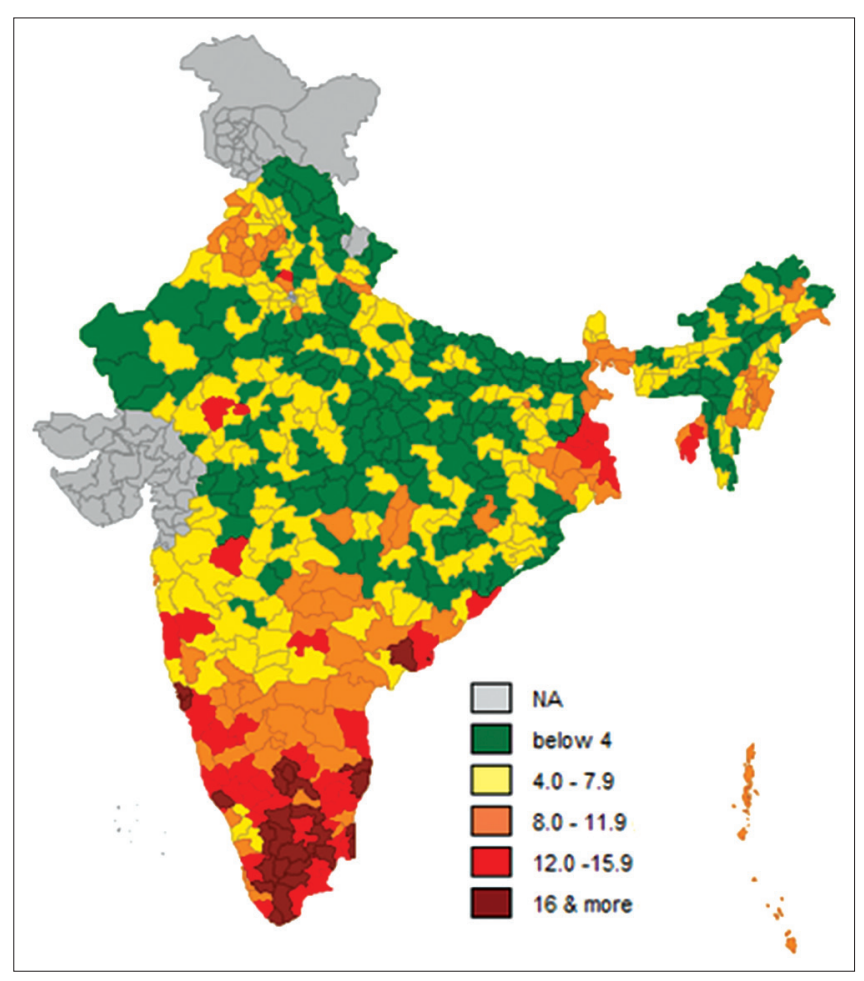

Figure 1: Map of prevalence of diagnosed diabetes in districts of India

only" diabetes as comparison to persons with normal BMI. The RRR among individuals with high blood pressure $(\mathrm{BP})$ is $1.6(P<0.01)$ for newly diagnosed and 1.4 for "self-reported only" diabetes in comparison to persons with ideal BP. The RRR among physically challenged respondents is $1.2(P<0.01)$ for newly diagnosed and 1.5 for "self-reported only" diabetes. The study also finds interesting results on the effects of smoking on diabetes, comparing to never smokers, ex-smokers have 1.1 higher RRR of "newly diagnosed," 1.2 greater risks of "self-reported only" diabetes.

\section{DISCUSSION}

The data on comparable incidence and prevalence of diabetes are scarce globally. International Diabetes Federation estimated $9.3 \%$ (age standardized by considering global population as standard) of Indians and $8.8 \%$ of World's adults with diabetes. ${ }^{[1]}$ Based on the national level surveys, the present study estimates
$7 \%$ adults diagnosed with diabetes and only $1.3 \%$ adults with self-reported diabetes in India. These figures are in the line of estimates available in few other studies. ${ }^{[1,2]}$ The big difference between diagnosed and self-reported diabetes also evident in other studies as nearly $50 \%$ of the population have undiagnosed diabetes in South Asia; ${ }^{[1]}$ though, the present study shows even more sharper differences. In particular, self-reported prevalence is lower than the reported in other national level survey. ${ }^{[33]}$ It can be noted that the illness status of all individuals was asked to the head of the household rather each; therefore, it may be under-reported. Nevertheless, the significant differences between diagnosed and self-reported suggest a need to strengthen the diagnosis system at the local level as a large proportion of the population is newly diagnosed with diabetes.

The present study further provides a higher prevalence of diagnosed diabetes in urban than the rural area. Other studies revealed diabetes prevalence in urban India increased ten-fold from $1.2 \%$ to $12.1 \%$ during 1971-2000. ${ }^{[35,36]}$ Moreover, the study estimates the higher prevalence of diabetes among males than females and similar sex differentials were found in other studies. ${ }^{[7]}$ Remarkably, most of the Southern states show the higher prevalence of diabetes and Kerala, Goa, and Tamil Nadu are among the states with highest diabetes prevalence. Overall, 28 districts where the prevalence of diagnosed diabetes is above $16 \%$ are from Southern India. These states are in the advanced stages of demographic and epidemiological transition and have more urban population. Further, the differentials in dietary intake among the states would have contributed to higher diabetes prevalence in particular states from Southern India and West Bengal. Tamil Nadu and Tripura are the states where the difference between diagnosed and self-reported is more prominent. States, namely Bihar, Madhya Pradesh, Odisha, and Himachal Pradesh have more rural population proportion and also have $<3.5 \%$ of diagnosed diabetes. Besides, nearly $40 \%$ of covered districts in India have $<4 \%$ of adults with diagnosed diabetes.

The study observes that males, older persons, urban residents, affluent, and educated persons have the higher 
risk of diabetes. Widows/widowers, older, wealthier, obese, and individuals with high BP have very high risk of both diagnosed and self-reported. These findings imply even their diabetic status was known, they had a weak diabetes management and therefore again diagnose with diabetes at the time of the survey. Strikingly, comparing to Hindus, Muslims and Christians have higher, while Sikhs have a lower risk of diabetes. These religious patterns may be attributed to the differentials in food consumption patterns among religion. Further, comparing to general caste, SCs and OBCs have the lower risk for "self-reported only" but have the higher risk of NDDs. In other words, comparing to general, persons from backward caste are less likely to go for diagnosis for diabetes. On the other hand, obese persons also have a higher risk of newly diagnosed. The present study also reveals that ex-smoking habit is positively related to diabetes rather than their current smoking behavior. Drinking alcohol has no significant association with diabetes though occasional drinkers have less risk of diabetes than who never drank alcohol.

\section{CONCLUSION}

With the increasing burden of diabetes in India, it is essential to provide the comparable prevalence of diabetes for states and districts. These estimates are acceptable because of the use of territory representative data sets and the uniform definition. Further, the age standardization has made prevalence more comparable in the country. New estimates might enable researchers, policy makers, and programmers to assess the district level burden of diabetes. The large differences between diagnosed and self-reported diabetes depict the higher rate of undiagnosed diabetes. Therefore, the study recommends the need to strengthen the diagnostics system at local level.

The study finds the high prevalence of diabetes among males, urban residents, in Southern India. Further, it also identifies the risk factors associated with "newly diagnosed," "self-reported only," and those who were diagnosed, as well as reported earlier with diabetes. Widows/widowers, older, wealthier, obese, and individuals with high BP have very high risk of both diagnosed and self-reported. Comparing to general, people from backward castes have less risk of self-reported but more risk of newly diagnosed with diabetes. Therefore, we recommend essential diabetes medicines and diagnostics to make accessible and affordable to those who need them the most. We further recommend for more studies need to be carried out to explore the factors affecting diabetes, particularly in high prevalent districts and states.
Although this study has used all suitable risk factors, however, it could not examine the association of diabetes with some of the key factors such as physical activity levels, dietary habits, occupation status, expenditure on treatments, and family history as information was not available in the data.

Financial support and sponsorship

Nil.

Conflicts of interest

There are no conflicts of interest.

\section{REFERENCES}

1. International Diabetes Federation (IDF). IDF Diabetes Atlas. $7^{\text {th }}$ ed. 2015. Available from: http://www.idf.org/idf-diabetesatlas-seventh-edition. [Last accessed on 2016 May 11].

2. World Health Organization. Global Report on Diabetes. 2016. Available from: http://www.who.int/diabetes/global-report/ en/. [Last accessed on 2016 May 11].

3. Danaei G, Finucane MM, Lu Y, Singh GM, Cowan MJ, Paciorek CJ, et al. National, regional, and global trends in fasting plasma glucose and diabetes prevalence since 1980: Systematic analysis of health examination surveys and epidemiological studies with 370 country-years and $2 \cdot 7$ million participants. Lancet 2011;378:31-40.

4. International Diabetes Federation (IDF. IDF Diabetes Atlas. $6^{\text {th }}$ ed. 2013. Available from: http://www.diabetesatlas.org/. [Last accessed on 2016 May 11].

5. World Health Organization. Global Health Observatory Data Repository. 2014. Available from: http://www.apps.who.int. [Last accessed on $2016 \mathrm{Jul} 20]$.

6. Mohan V, Sandeep S, Deepa R, Shah B, Varghese C. Epidemiology of type 2 diabetes: Indian scenario. Indian J Med Res 2007;125:217-30.

7. Ramachandran A, Snehalatha C, Kapur A, Vijay V, Mohan V, Das AK, et al. High prevalence of diabetes and impaired glucose tolerance in India: National Urban Diabetes Survey. Diabetologia 2001;44:1094-101.

8. Liu S, Manson JE, Stampfer MJ, Hu FB, Giovannucci E, Colditz GA, et al. A prospective study of whole-grain intake and risk of type 2 diabetes mellitus in US women. Am J Public Health 2000;90:1409-15.

9. Bennett PH. Type 2 diabetes among the Pima Indians of Arizona: An epidemic attributable to environmental change? Nutr Rev 1999;57(5 Pt 2):S51-4.

10. Aksu H, Pala K, Aksu H. Prevalence and associated risk factors of type 2 diabetes mellitus in Nilufer District, Bursa, Turkey. Int $\mathrm{J}$ Diabetes Metab 2006;14:98.

11. Prasad RB, Groop L. Genetics of type 2 diabetes - Pitfalls and possibilities. Genes 2015;6:87-123.

12. Diamond J. The double puzzle of diabetes. Nature 2003;423:599-602.

13. Nagpal J, Bhartia A. Quality of Diabetes care in the middle- and high-income group populace: The Delhi Diabetes Community (DEDICOM) survey. Diabetes Care 2006;29:2341-8.

14. Yadav S, Boddula R, Genitta G, Bhatia V, Bansal B, Kongara S, et al. Prevalence \& risk factors of pre-hypertension and hypertension in an affluent North Indian population. Indian J Med Res 2008;128:712-20. 
15. Jayawardena R, Ranasinghe P, Byrne NM, Soares MJ, Katulanda P, Hills AP. Prevalence and trends of the diabetes epidemic in South Asia: A systematic review and meta-analysis. BMC Public Health 2012;12:380.

16. Ahuja MM, editor. Epidemiological studies on diabetes mellitus in India. In: Epidemiology of Diabetes in Developing Countries. New Delhi: Interprint; 1979. p. 29-38.

17. World Health Organization. Diabetes Mellitus: Report of a WHO Study Group. (Tech. Rep. Ser., No. 727). Geneva: World Health Organization; 1985.

18. Sridhar GR, Rao PV, Ahuja MM. Epidemiology of diabetes and its complications. In: RSSDI Textbook of Diabetes Mellitus. Hyderabad: Research Society for the Study of Diabetes in India; 2002. p. 95-112.

19. World Health Organization. The World Health Report, 1999: Making a Difference: Message from the Director-General. Geneva: World Health Organization; 1999.

20. Zargar AH, Khan AK, Masoodi SR, Laway BA, Wani Al, Bashir MI, et al. Prevalence of type 2 diabetes mellitus and impaired glucose tolerance in the Kashmir Valley of the Indian subcontinent. Diabetes Res Clin Pract 2000;47:135-46.

21. Zaman FA, Pal R, Zaman GS, Swati IA, Kayyum A. Glucose indices, frank and undetected diabetes in relation to hypertension and anthropometry in a South Indian rural population. Indian $\mathrm{J}$ Public Health 2011;55:34-7.

22. Menon VU, Kumar KV, Gilchrist A, Sugathan TN, Sundaram KR, Nair V, et al. Prevalence of known and undetected diabetes and associated risk factors in central Kerala - ADEPS. Diabetes Res Clin Pract 2006;74:289-94.

23. Shah SK, Saikia M, Burman NN, Snehalatha C, Ramachandran A. High prevalence of type 2 diabetes in urban population in North Eastern India. Int J Diabetes Dev Ctries 1999;19:144-7.

24. Kutty VR, Soman CR, Joseph A, Pisharody R, Vijayakumar K. Type 2 diabetes in Southern Kerala: Variation in prevalence among geographic divisions within a region. Natl Med J India 2000;13:287-92.

25. Sadikot SM, Nigam A, Das S, Bajaj S, Zargar AH, Prasannakumar KM, et al. The burden of diabetes and impaired glucose tolerance in India using the WHO 1999 criteria:
Prevalence of diabetes in India study (PODIS). Diabetes Res Clin Pract 2004;66:301-7.

26. Ajay VS, Prabhakaran D, Jeemon P, Thankappan KR, Mohan V, Ramakrishnan $\mathrm{L}$, et al. Prevalence and determinants of diabetes mellitus in the Indian industrial population. Diabet Med 2008;25:1187-94.

27. Gupta A, Gupta R, Sarna M, Rastogi S, Gupta VP, Kothari K. Prevalence of diabetes, impaired fasting glucose and insulin resistance syndrome in an urban Indian population. Diabetes Res Clin Pract 2003;61:69-76.

28. Chow CK, Raju PK, Raju R, Reddy KS, Cardona M, Celermajer DS, et al. The prevalence and management of diabetes in rural India. Diabetes Care 2006;29:1717-8.

29. Vijayakumar G, Arun R, Kutty VR. High prevalence of type 2 diabetes mellitus and other metabolic disorders in rural central Kerala. J Assoc Physicians India 2009;57:563-7.

30. Ravikumar P, Bhansali A, Ravikiran M, Bhansali S, Walia R, Shanmugasundar G. et al. Prevalence and risk factors of diabetes in a community-based study in North India: The Chandigarh Urban Diabetes Study (CUDS). Diabetes Metab 2011;37:216-21.

31. Vaz NC, Ferreira AM, Kulkarni MS, Vaz FS. Prevalence of diabetes mellitus in a rural population of Goa, India. Natl Med J India 2011;24:16-8.

32. Arokiasamy P, Parasuraman S, Sekher TV, Lhungdim H. International Institute for Population Sciences. Geneva: World Health Organization; 2013.

33. Ministry of Health and Family welfare, Government of India, International Institute for Population Science, Deonar, Mumbai, 2014. District Level Household and Facility Survey (DLHS 4). 2012-2013. Available from: http://www.nrhmmis.nic.in/SitePages/ DLHS-4.aspx. [Last accessed on 2016 Mar 18].

34. Office of the Registrar General and Census Commissioner (India). India Annual Health Survey 2012-2013. Available from: http:// www.censusindia.gov.in/2011census/hh-series/cab.html. [Last accessed on 2016 Mar 18].

35. Ramachandran A. Epidemiology of diabetes in India - Three decades of research. J Assoc Physicians India 2005;53:34-8.

36. Pradeepa R, Mohan V. The changing scenario of the diabetes epidemic: Implications for India. Indian J Med Res 2002;116:121-32. 